This is the accepted version (post-print) of

Coelho, G. L. H., Monteiro, R. P., Hanel, P. H. P., Vilar, R., Gouveia, V. V., \& Maio, G. R. (2018). Psychometric parameters of an abbreviated vengeance scale across two countries. Personality and Individual Differences, 120, 185-192.

https://doi.org/10.1016/j.paid.2017.08.042

\title{
Psychometric parameters of an abbreviated vengeance scale across two
} countries

\author{
Gabriel L. H. Coelho ${ }^{\text {a }}$ \\ Renan P. Monteiro ${ }^{b}$ \\ Paul H. P. Hanel ${ }^{\mathrm{c}}$ \\ Roosevelt Vilar ${ }^{\mathrm{d}}$ \\ Valdiney V. Gouveia ${ }^{\mathrm{e}}$ \\ Gregory R. Maio ${ }^{\mathrm{c}}$
}

${ }^{\text {a }}$ Cardiff University, United Kingdom.

${ }^{\mathrm{b}}$ Federal University of Piauí, Brazil.

c University of Bath, United Kingdom.

${ }^{\mathrm{d}}$ Massey University, New Zealand.

${ }^{\text {e }}$ Federal University of Paraíba, Brazil.

Corresponding authors: (Gabriel Coelho) linshc@gmail.com ; (Renan Monteiro) renanpmonteiro@gmail.com

Correspondence address: Valdiney V. Gouveia (vvgouveia@gmail.com), Department of Psychology, Federal University of Paraiba, 58.051-900 Joao Pessoa, PB, Brazil. 


\begin{abstract}
We propose a short and ultrashort version of the Vengeance Scale (Stuckless \& Goranson, 1992). Across three samples, good psychometric properties and convergent validity for the new scales were found. Study 1 found in a Brazilian sample that the original 20 items can be reduced to both a 10 and 5 item version (VS-10 and VS-5), without losing psychometric quality. In Study 2, the one-factorial structure was confirmed in a Brazilian and a British sample. Also, (partial) measurement invariance was established across gender and countries for the VS-10, but not for the VS-5. Across both samples, the short-versions correlated as expected with the Big-5, Big-6, and Dark Triad. Overall, the 10- and 5-item versions of the vengeance scale exhibited comparable reliabilities and validities to the full version.
\end{abstract}

Keywords: vengeance; measurement; personality; validation; transcultural. 
"Haste me to know 't, that I, with wings as swift As meditation or the thoughts of love, May sweep to my revenge." W. Shakespeare, Hamlet

\section{Introduction}

Extreme hurts, such as suffering a betrayal, assault, or slander, can elicit strong emotional reactions. Some people are willing to forgive those who hurt them, whereas others prefer to "get even" by seeking revenge against the transgressor. Numerous studies have examined the latter propensity to seek vengeance (e.g., Cota-McKinley, Woody, \& Bell, 2001; Schumann \& Ross, 2010). Vengeance can be defined as "the infliction of harm in return to perceived wrong" (Stuckless \& Goranson, 1992, p. 25). The act of vengeance can vary in magnitude, according to the seriousness of the first attack, the transgressor's intentionality, and the proximity to the victim (Gollwitzer \& Denzler, 2009; Schumann \& Ross, 2010).

McCullough, Bellah, Kilpatrick, and Johnson (2001) suggest that three main goals underpin vengeance. First, vengeance as balancing the scales, where the individual sees the act as truly moral, restoring the equilibrium with the aggressor or "getting even". Second, vengeance as moral instruction, where the act works as a moral-educative reaction, to show the offender that a particular type of behavior is not acceptable in society. Finally, vengeance as saving face, as an attempt to show the aggressor the victim's value or self-worth and that he or she needs respect and dignity.

To the revenger, the act of vengeance can promote the idea of justice, especially when the transgressor knows that vengeance is a reaction to a previous behavior (Gollwitzer \& Denzler, 2009; Gollwitzer, Meder, \& Schmitt, 2011). Besides the direct message to the transgressor, vengeance can also be interpreted as a message to those with similar characteristics, proximity and connection to the transgressor, advising others not 
to mess with the victim (Sjöström \& Gollwitzer, 2015). Thus, even when considered an immature and unethical reaction, vengeance can present adaptive functions by keeping the victim away from potential transgressors (Grobbink, Derksen, \& Marle, 2014; McCullough, 2008).

Because of its relevance to everyday life, researchers have aimed to get a better understanding of the antecedents and correlates of vengeance behavior. The scale used most often was developed by Stuckless and Goranson (1992). Their 20-item Vengeance Scale measures attitudes toward revenge. In the development process of the scale, 600 individuals participated across three studies. The factor analysis performed across the studies showed a multidimensional distribution of the items. However, the first factor explained more than $40 \%$ of the variance, while the other factors explained less than $9 \%$ of the variance. Thus, the Stuckless and Goranson argued that it is best to assume a onedimensional structure. Also, the studies provided evidence for the measure's validity, internal consistency $(\alpha=.92)$, and high test-retest reliability over five weeks $(r=.90, p<$ .001). The convergent validity was demonstrated by correlations with different measures such as empathy $(r=-.33, p<.001)$ and anger $(r=.42, p<.001)$.

The scale has been used in numerous studies on diverse topics, including perceptions of violence following a betrayal by a romantic partner (Forbes, Jobe, White, Bloesch, \& Adams-Curtis, 2005), human values (McKee \& Feather, 2008), religious orientation (Greer, Berman, Varan, Bobrycki, \& Watson, 2005), reappraisal and aggressive behavior (Barlett \& Anderson, 2011), and subjective happiness and forgiveness (Uysal \& Satici, 2014). The scale also exhibits good psychometric properties in different cultures and languages, including Italian (Ruggi, Gilli, Stuckless, \& Oasi, 2012), Turkish (Satici, Can, \& Akin, 2015), and Japanese (Sawada \& Hayama, 2012). 
Other studies have focused on relations between attitudes towards vengeance and personality. As Ruggi et al. (2012) emphasize, "a dispositional and trait-based interpretation of personality would define vengeance as an individual phenomenon that is quite stable and dependent on the individual's psychic and experimented features" (p. 366), which points to a close relation between those constructs. For example, these authors found significant correlations between vengeance and energy $(r=.19, p<.001)$, friendliness $(r=-48, p<.001)$, conscientiousness $(r=-.14, p<.001)$ and emotional stability $(r=-.26, p<.001)$. In another study, Sheppard and Boon (2012) found significant correlations between vengeance and honesty-humility $(r=-.40, p<.001)$ and agreeableness $(r=-.42, p<.001)$.

Although the vengeance scale provides consistent results and important findings across the world, its length can be a potential issue, especially in research environments relying on quick assessments (e.g., online or field studies) or that require steps to minimize participant fatigue, inattentiveness, or boredom (e.g., due to multiple additional measures, arduous tasks). These pressures raise the need for a shorter scale. Short-form "may substantially increase both the Type 1 and Type 2 error rates" (Credé, Harms, Niehorster, \& Gaye-Valentine, 2012, p. 874), because of possible failures when assessing their reliability and validity (Rammstedt \& Beierlein, 2014). Nonetheless, researchers have attempted to address these issues while rigorously developing and testing a number of short scales in recent years (Gosling, Rentfrow, \& Swann, 2003; Rammstedt \& John, 2007; Widaman, Little, Preacher, \& Sawalani, 2011; Yarkoni, 2010). In the present research, we sought to balance the concerns about short-form scales with their utility by rigorously developing and evaluating both a short and an ultrashort version of the Vengeance Scale, which contain 10 and 5 items, respectively. 


\section{The present research}

The current studies developed a short and ultrashort version of the Vengeance

Scale. We tested the psychometric properties through different techniques (e.g., Item Response Theory, exploratory factor analysis, confirmatory factor analysis), and we examined its convergent validity with personality traits. To achieve these aims, we conducted two studies with three samples: two Brazilian samples (Study 1 and 2) and one British sample (Study 2). This design allowed us to test for measurement invariance (equivalence) of the shortened versions of the scale across countries. This type of analysis was not performed in previous validations, leaving unaddressed whether the measure differs regarding people's culture or gender, for example.

In Study 1, an exploratory factor analysis was performed, with the best items selected through Item Response Theory in the Brazilian sample. In Study 2, we conducted confirmatory factor analysis and factorial invariance tests to confirm the proposed structure in samples from Brazil and United Kingdom. The datasets for all three samples can be found on https://osf.io/f87gm/?view_only=535394772041474b8f8722418eaf76cc

\section{Study 1}

\section{Method}

3.1. Participants. Participants were 202 individuals, with a mean age of 25.60 (SD $=7.78), 56.4 \%$ female.

3.2. Material and Procedure. Data was collected through an online questionnaire. Participants were recruited through social media (e.g., Facebook), where the link was made available. The online questionnaire provided information about how to proceed with the study and contact details of the researchers. Participants completed the following scales. 
Vengeance Scale (Stuckless \& Goranson, 1992). It was developed as a measure of attitudes toward revenge and consists of 20 items. Example items include "I don't just get mad, I get even" and "I try to even the score with anyone who hurts me". Participants are asked to what extent they agree with these sentences, answering on a seven-point scale (1 = Disagree Strongly; 7 = Agree Strongly) .

A Ten-Item Personality Inventory (TIPI; Gosling et al., 2003). This scale was developed to measure the Big Five personality factors (Extraversion, Agreeableness, Conscientiousness, Emotional Stability, and Openness to Experiences). Participants answer the inventory using a seven-point scale $(1=$ Disagree Strongly; $7=$ Agree Strongly) and examples of characteristics include "Critical, quarrelsome" and "Anxious, easily upset".

3.3. Data Analysis. The data was analyzed using the software Factor 10.3 .01 (Lorenzo-Seva \& Ferrando, 2013) and R (R Development Core Team, 2015). Factor 10.3.01 was used to evaluate the factorial structure of the vengeance scale, using Exploratory Maximum Likelihood (ML) method. R was used to calculate the individual parameters of the items, using the MIRT (Multidimensional Item Response Theory; Chalmers, 2012), package to assess the threshold, discrimination, and informative curve of each item. Due to the polytomous nature of the measure, the Graded Response Model (Samejima, 1968) was used.

\section{Results}

Both the Kaiser-Meyer-Olkin (.93) and Bartlett's Test of Sphericity [2551.9(190), $p<.001]$ showed a good fit to the data, allowing us to perform an exploratory factor analysis (Field, 2013). An exploratory factor analysis, using ML, resulted in a two-factor solution with eigenvalues > 1 (9.67 and 1.82). However, the Hull Method, which is considered one of the most efficient in determining the exact number of factors (Lorenzo- 
Seva, Timmerman, \& Kiers, 2011), showed a one-factor solution, explaining $48 \%$ of the total variance.

\section{[TABLE 1]}

As it can be seen in Table 1, all items loaded above .40, varying from .47 (Item 19. "To have a desire for vengeance would make me feel ashamed") to .88 (Item 2. "It is important for me to get back at people who have hurt me"), except Item 8 ("I find it easy to forgive those who have hurt me"), which provided a poor loading. Next, we performed an IRT to further evaluate the vengeance scale. Specifically, we tested the capacity of the items to discriminate between people and spread in the thresholds and information. Because of the 7-point response scale, there are 7-1 $=6$ thresholds.

The capacity of items to discriminate between people was strong, varying from moderate (item 8) to very high (item 2; Baker, 2001). The most discriminative items, as indicated by the discrimination parameter a, were items 2,7 , and 1 . The item threshold analysis further indicates the level of the latent trait that a participant need to have to endorse to select the next higher option category. This can be examined by the values of the thresholds, such that lower values of $b_{1-6}$ indicate that the item is "easier" to answer (i.e., a lower item threshold), and higher values of $b_{1-6}$ indicate a higher item threshold and thus more "difficultly". In general, items 8 and 15 have the lowest and the highest average thresholds: the average threshold for item 8 is -.91 and 1.67 for item 15 . For the detailed results see Table 1. Finally, the test information curve was assessed, and results provided a reasonable spread of discrimination across the latent range (Figure 2).

The test information curve is a graphical representation of items' contribution to the total information (Castro, Trentini, \& Riboldi, 2010). This test enabled us to select the items that share more information and, consequently, are more central to the construct (see Figure 1). Thus, the less informative items were excluded $[\mathrm{I}(\theta)<1,0]$, maintaining a 
total of 11 items that were more central to the scale. Additionally, item 17 (Anyone who provokes me deserves the punishment that I give them) was also excluded, due to conceptual issues: The item can be considered a double-barrelled item because it implies deservingness of punishment and that the individual "gives punishment". We then calculated the threshold and discrimination of these 10 items for the short version of the VS (Table 2). All of them showed high discrimination $(M=2.92 ; S D=0.91)$, with items covering a wide range of the latent trait (between -1.03 to 3.46), while being neither too easy nor too difficult ( $b_{1}$ to $b_{6}$ averages between 0.78 and 1.69).

[FIGURE 1]

[TABLE 2]

Next, a comparison of the information curves of the scale from these 10 items and the full version revealed that removing the nine least informative items and the doublebarrelled item did not result in a loss of information (Figure 2). In a next step, we selected from the 10 items those with psychometric information above two $[\mathrm{I}(\theta)>2.0]$ to compose an ultrashort version of the vengeance scale (VS-5). The discrimination and the threshold parameters (Table 3) show that the five-item version presents enough evidence of quality, being more precise in the range between .5 and 1.5. As can be seen in Figure 2, the information tests show how precise the measures are, with all three versions accurately evaluate people with ability levels between -1.5 and 3.5. Thus, the 10 and 5 selected items were all suitable to create a short and an ultrashort version of the vengeance scale (VS-10 and VS-5; see Appendix for the items in English and Portuguese).

[TABLE 3]

[FIGURE 2] 
As predicted, the correlations with the Big Five supported the validity of the short version, showing a similar pattern of results for the three versions of the scale. Vengeance exhibited very similar negative correlations with agreeableness (VS-20, $r=-.31, p<.01$; VS-10, $r=-.28, p<.01 ; \mathrm{VS}-5, r=-.29, p<.01$ ), emotional stability (VS-20, $r=-.15, p<$ $.05 ; \mathrm{VS}-10, r=-.13, p>.05 ; \mathrm{VS}-5, r=-.12, p>.05)$. The VS-5 also presented a significant correlation with openness to experiences $(r=-.15, p<.05$; VS, $r=-12, p>$ .05 ; VS-10, $r=-.13, p>.05)$. Finally, all three versions presented the same coefficients of internal consistency (to two decimal places) using McDonald's omega and Cronbach's alpha ( $\omega$ and $\alpha=.94)$. Thus, the VS-10 and VS-5 present very similar psychometric properties to the longer version (Kline, 2013).

\section{Study 2}

\section{Method}

4.1. Participants. The Brazilian sample consisted of 220 individuals with a mean age of 28.94 years $(S D=11.52,65.9 \%$ women $)$. British participants were 205 individuals, with mean age of $19.59(S D=2.35,87.3 \%$ women $)$.

4.2. Material and Procedure. In Brazil, participants completed the survey online via social networks, and by paper and pen. In the UK, participants completed an online questionnaire in exchange for course credits. Participants in each country completed the vengeance scale and the personality measures described below.

In Brazil, participants completed the International Personality Item Pool-6 (Sibley et al., 2011). This scale measures the Big Six personality factors (extraversion, agreeableness, conscientiousness, neuroticism, openness to new experiences, and honesty-humility). Examples items are "I feel others' emotions" (agreeableness) and "I deserve more things in life" (honesty-humility, reverse coded). Participants used on a 
seven-point scale $(1=$ Very Inaccurate $; 7=$ Very Accurate $)$ to indicate the extent to which each statement described them.

Brazilian participants also completed the Dirty Dozen scale (Jonason \& Webster, 2010), which measures the Dark Triad of personality (narcissism, Machiavellianism, and psychopathy). Example items include, "I tend to lack remorse" (psychopathy) and "I tend to exploit others towards my own end" (Machiavellianism). Participants answered rated the extent to which the statements described them using a five-point scale $(1=$ Strongly

Disagree; 5 = Strongly Agree).

In the UK, participants answered the Mini-IPIP (Donnellan, Oswald, Baird, \& Lucas, 2006), a 20-item short questionnaire to measure the five big factors of personality (Extraversion, Agreeableness, Conscientiousness, Neuroticism, and Openness to Experiences). Examples of items include "I have frequent mood swings" and "I get upset easily" (both neuroticism). Responses were given using a five-point scale, ranging from 1 (very inaccurate) to 5 (very accurate).

4.3. Data Analysis. Data was analyzed with R software (R Development Core Team, 2015), using lavaan package (Rosseel, 2012). The one-factor structure of the VS10 and VS-5 were assessed using confirmatory factor analysis (CFA) with Robust Maximum Likelihood (MLR) estimator. This estimator is robust to the non-normality of data, and it is also recommended for categorical-ordinal data when the response scale has 5 or more points (Rhemtulla, Brosseau-Liard, \& Savalei, 2012). The following indices were used with thresholds recommended in the literature (Hair, Black, Babin, \& Anderson, 2015; Hooper, Coughlan, \& Mullen, 2008; Tabachnick \& Fidell, 2013). First, the chi-square $(\chi 2)$, which must be non-significant. However, because this test is sensitive to sample sizes, we focused on Comparative Fit Index (CFI) and Tucker-Lewis 
Index (TLI), each of which require to be higher than .90 for a good model fit. Finally, the Root mean square error approximation (RMSEA) was used, which should be below .08 .

To ensure that the short versions of the VS can be used for comparisons through different groups, the measurement invariance need to be established. This is important because one might otherwise end up comparing "chopsticks with forks" (Chen, 2008). That is, when invariance is not achieved, the meaning attributed to the items might differ across groups. To test the invariance of the measure across the participants' country and gender, multigroup CFAs were performed. We tested whether invariance was established across three models (Damásio, 2013; Milfont, \& Fischer, 2010). It was argued that these three levels of measurement invariance need to be established, before means and correlation coefficients can be meaningfully compared across groups (Davidov, Meuleman, Cieciuch, Schmidt, \& Billiet, 2014) : (1) Configural invariance, which requires the factorial structure to be invariant across groups; (2) metric invariance, which requires the loadings between observed items and latent variables to be invariant across groups; and (3) scalar invariance, which requires the indicator intercepts to be invariant across groups. The following parameters were used as thresholds: $\triangle \mathrm{CFI}$ and $\triangle \mathrm{RMSEA}$, which must be equal or below .010 and .015, respectively (Chen, 2007), when a model was compared with the next higher one (e.g., the model for which only the factorial structure was restricted across groups with the model where the loadings was additionally restricted). After establishing that the vengeance scale is invariant across gender, the means for each gender were compared across countries using a two-way ANOVA. Finally, to provide evidence of convergent validity, we examined the correlations between the VS-10 and VS-5 with the Big Six factors of personality. 


\section{Results}

First, the data from the Brazilian and British samples were analyzed separately. The samples were then combined to test for measurement invariance between countries and gender.

\subsection{Brazil}

To test the one-factor structure, two CFAs were performed. For the VS-10, all indicators indicated good fit to this structure: $\chi^{2}(35)=76.75(p<.001)$, CFI $=.95$, TLI $=$ .93 , and RMSEA $=.07(\mathrm{CI} 90 \%=.054-.093)$. All the factorial weights (lambdas) were statistically different from zero $(\lambda \neq 0 ; \mathrm{z}>1.96, p<.05)$, varying between .61 (Item 4 , in the original 20-item numeration) and .86 (Item 2). For the VS-5, all indicators indicated good fit to this structure: $\chi^{2}(5)=10.42(p>.05)$, CFI $=.98$, TLI $=.96$, and RMSEA $=.07$ $(\mathrm{CI} 90 \%=.000-.125)$, with lambdas varying from .66 (Item 9 , in the original 20 -item numeration) to .87 (Item 6). Additionally, internal consistency was high in both versions (VS-10, $\omega$ and $\alpha=.92 ;$ VS-5, $\omega$ and $\alpha=.88 ;$ Kline, 2013).

Next, we examined the correlations between the VS scales and the Big Six factors of personality and the Dark Triad. Vengeance was positively correlated with neuroticism (VS-10 and VS-5, $r=.19, p<.01)$ and negatively correlated with agreeableness (VS-10, $r=-.28, p<.001 ; \mathrm{VS}-5, r=-.27, p<.01)$, conscientiousness $(\mathrm{VS}-10, r=-.22, p<.001$; VS-5, $r=-.24, p<.01$ ), and honestylhumility (VS-10 and VS-5, $r=-.40, p<.001$ ). Also, both the VS-10 and VS-5 scales correlated positively with all factors in the Dark Triad (psychopathy, $r=.38$ and .36 , respectively, $p<.001$; Machiavellianism, $r=.31$ for both scales, $p<.001$; narcissism, $r=.19$ and .18 , respectively, $p<.01)$.

\subsection{United Kingdom}

The CFA indicators revealed good fit to the one-factor structure for the VS-10 in the British sample: $\chi^{2}(35)=71.12(p<.001)$, CFI $=.94$, TLI $=.93$, and RMSEA $=.07$ 
(CI 90\% $=.050-.093)$. All the factorial weights (lambdas) were statistically different from zero $(\lambda \neq 0 ; \mathrm{z}>1.96, \mathrm{p}<.05)$, varying between .35 (Item 1) and .88 (Item 2). For the VS5 , once again, the fit indices were very good, $\chi^{2}(5)=3.01(p>.05)$, CFI $=1$, TLI $=1.02$ and RMSEA $=0($ CI90\% $=0-.065)$, varying between .37 (Item 1) and .88 (Item 2). Once again, both versions exhibited satisfactory-to-high reliability (VS-10, $\omega=.89$, and $\alpha=$ $.88 ; \mathrm{VS}-5, \omega=.79$, and $\alpha=.78 ;$ Kline, 2013).

The relations with personality that were found in the Brazilian sample were replicated in the British sample. That is, vengeance was positively correlated with neuroticism (VS-10, $r=.25, p<.001$; VS-5, $r=.24, p<.001)$ and negatively with

agreeableness (VS-10, $r=-.25, p<.001$; VS-5, $r=-.21, p<.001$ ), and conscientiousness $(\mathrm{VS}-10, r=-.14, p<.05, \mathrm{VS}-5, r=-.13, p=.06)$.

Analyzing both samples together, the fit indices for the VS-10 were good: $\chi^{2}(35)$ $=130.06(p<.001), \mathrm{CFI}=.93, \mathrm{TLI}=.91$, and RMSEA $=.08(\mathrm{CI} 90 \%=.068-.093)$. The VS-5 also showed good fit indices: $\chi^{2}(5)=9.498(p>.05)$, CFI $=.99$, TLI $=.98$, and RMSEA $=.05($ CI 90\% $=.0-.085)$.

\subsection{Measurement Invariance}

Thus, after having established that the data support a one-factor structure of the VS-10 and VS-5, two Multi-Group Confirmatory Factor Analysis were used to test for measurement invariance. Specifically, we tested whether participants from Brazil and the United Kingdom, and whether women and men across countries responded to the items in the same way. This test considered three models (configural, metric and scalar). It is necessary to have three levels of measurement invariance established in order to compare means and correlations across countries (e.g., Davidov et al., 2014). As can be seen in Table 4, measurement invariance for countries was established only on the first level. If measurement invariance is not established, an alternative approach is to unconstrain 
(free) one or more items based on the modification indices (Byrne, Shavelson, \& Muthén, 1989). If this leads to a $\Delta \mathrm{CFI}$ lower or equal to .01, partial measurement equivalence is established (Chen, 2007). After freeing item 2 ("It is important for me to get back at people who have hurt me") of the VS-10, partial metric invariance was established. After freeing item 1 ("It's not worth my time or effort to pay back someone who has wronged me") and item 9 ("If I am wronged, I can't live with myself unless I get revenge"), scalar invariance was also established. These results indicate that the VS-10 is mainly invariant across countries, as participants understood most items in a similar way. However, for the VS-5, measurement invariance was not established. First, the loadings of item 2 and 6 had to be unconstrained to achieve even partial metric invariance. However, scalar invariance was not even reached after freeing item 1, 6, and 7, whose intercepts differed significantly from each other. The VS-10 and VS-5 differed regarding the measurement invariance because differences in item loadings and intercepts across countries matter more for shorter scales than for longer versions. Thus, comparing correlation coefficients and means across Brazil and the UK can only be done in a meaningful way for the VS-10 scale.

In contrast, full measurement invariance was established regarding participants' gender across countries in both versions. A separate analysis for gender within each country was not possible because of the unequal gender ratio, especially in the UK (87\% women).

\section{[TABLE 4]}

Finally, we compared the mean scores across country and gender. For each of the two comparisons, we compared two models. In the first model, we constraint only loadings, intercepts, and residuals. In the second model, we additionally constraint the means. For the country comparison, we let the three items unconstraint, which were 
found to be variant in the MGCFA. The country comparison was significant. Britons scored higher on vengeance $(M=2.77, S D=0.92)$ than did Brazilians $(M=2.30, S D=$ $1.14 ; \chi^{2}(1)=60.25, p<.001$. In contrast, men did not score higher on vengeance $(M=$ 2.67, $S D=1.10)$ than did women $\left(M=2.48, S D=1.05 ; \chi^{2}(1)=2.86, p=.09\right)$.

\section{General Discussion}

The main objective of this research was to test the reliability and validity of a short and ultra-short version to the Vengeance Scale across two countries. We first discuss the structure of the VS-10 and VS-5, then the measurement invariance, and finally the external validity.

\subsection{One-factor structure and item parameters}

In Study 1, the exploratory factor analysis showed the expected one-factor solution, with all the items presenting satisfactory loadings (Ruggi et al., 2012; Satici et al., 2015; Sawada et al., 2012; Stuckless \& Goranson, 1992). To reduce the number of items in the scale, we tested alternative shorter versions using Item Response Theory. This type of analysis was not performed in previous research. All items were discriminative when evaluating different levels of vengeance. Next, we chose the items described as more informative, which made possible to reduce the scale by $50 \%$, with almost no loss of psychometric information. Also, an ultra-short version was considered, with five of the original 20 items.

We further tested the psychometric quality of the VS-10 and VS-5 in Study 2. Study 2 tested the structure of these measures in Brazil and the United Kingdom. The results in both countries supported the psychometric quality of the VS-10 and VS-5.

\subsection{Measurement invariance and differences regarding country and gender}

Measurement invariance was assessed by comparing the results across three levels of measurement. This test helps to establish whether correlations and means can be 
compared across countries and gender (Chen, 2008; Davidov et al., 2014). Across both countries, the VS-10 and VS-5 were only partly invariant. Specifically, for the VS-10, seven items were invariant, whereas three items were less so, while for the VS-5 measurement invariance was not achieved. However, as three out of ten items present only a small minority, the overall VS-10 scale can be compared across countries. Regarding participants' gender, the VS-10 and VS-5 were invariant. This means that both men and women answered the instrument in the same way. Thus, the VS-10 can be used to compare people from different countries and gender, whereas the VS-5 should only be used for gender comparisons.

Also, our results showed significant differences across gender and country. Regarding gender, we replicated Stuckless and Goranson (1992) findings that men scored higher in vengeance than women. Regarding national differences, British participants were more vengeful than Brazilian participants. This finding is somewhat surprising, given that the homicide rate, which is presumably partly related to vengeful behavior, is 25 times higher in Brazil than in the UK (United Nations Office on Drugs and Crime, 2014). Also, other variables related to being vengeful, such as neuroticism and openness (McCrae \& Terracciano, 2005) or self-esteem (Schmitt \& Allik, 2005), barely differ between Brazil and the UK. Thus, future (cross-cultural) research is needed to explain this surprising finding.

\subsection{Correlations with personality}

This research examined relations between vengeance and personality traits across two cultures. In both cultures, we found that increased positivity to vengeance was associated with lower agreeableness and higher neuroticism, as found in previous studies (McCullough et al., 2001; McCullough \& Hoyt, 2002). Low agreeableness is related to aggressiveness, emphatic deficits, and difficulties developing close relationships and 
selfishness - all characteristics that can accentuate a willingness to take revenge (Cavalcanti \& Pimentel, 2016; Ruggi et al., 2012). High neuroticism predisposes people to more intensely experience negative emotions, such as anger, and to ruminate about negative events, which may elicit strong negative emotions and reactions towards a transgressor (Barber, Maltby, \& Macaskill, 2005; McCullough \& Hoyt, 2002).

Higher positivity toward vengeance was also linked with low conscientiousness and honesty-humility. Low conscientiousness implies lower self-control, which makes it difficult to control the expression of momentary anger and threatens the maintenance of a long-term relationship (Balliet, 2010). Therefore, people who score low on conscientiousness are expected to react aggressively against their transgressors. Low honesty-humility relates to antisocial behaviors and a sense of entitlement, potentially predisposing people to a reaction when the individual is irritated or provoked (Lee \& Ashton, 2012). These reactions may serve as a message to the transgressor, indicating that there will be punishment in case of new provocations.

In the second study, we also assessed the association between vengeance and the Dark Triad of personality in a Brazilian sample, and the results indicated that higher vengeance was associated with higher scores on all three Dark Triad traits: narcissism, psychopathy, and Machiavellianism. Vengeance correlated strongest with psychopathy and Machiavellianism. These traits are sometimes called Dark Dyad, due their particularly strong relations with antisocial behaviors (Giammarco \& Vernon, 2014; Pailing, Boon, \& Egan, 2014). In addition, the relation between vengeance and narcissism is consistent in other studies (e.g., Brown, 2004; Jones \& Paulhus, 2010; Rasmussen, 2015): when a narcissistic people suffer a real, or perceived, provocation, they react aggressively or in a vengeful way. Of interest, these relations are also consistent with the 
personality trait relations described above, because the Dark Triad is negatively related to honesty-humility (Lee \& Ashton, 2005).

\section{Final remarks and future studies}

This research provided strong psychometric support for a short version of the Vengeance Scale (VS-10), including evidence for its convergent validity with various personality traits. This scale can help researchers to examine how attitudes to vengeance relate to diverse relevant variables. Furthermore, the evidence presented here indicates that the VS-10 may be well suited to studies across cultures. The ultrashort version, the VS-5, is appropriate within nations where very brief measurement is imperative.

Together, these new measures enable interesting novel examinations of psychological processes linking vengeance and diverse social behaviors in the context of important contemporary issues, such as honor crimes.

\section{Acknowledgments}

The authors acknowledge financial support from the Coordination for the Improvement of Higher Education Personnel (CAPES, Brazil, http://www.capes.gov.br/) to the first author, and National Council for Scientific and Technological Development (CNPq, Brazil, http://cnpq.br/) to the fourth author.

\section{References}

Baker, F. B. (2001). The Basics of Item Response Theory. Second Edition. Retrieved from http://eric.ed.gov/?id=ED458219

Balliet, D. (2010). Conscientiousness and forgivingness: A meta-analysis. Personality and Individual Differences, 48(3), 259-263. http://dx.doi.org/10.1016/j.paid.2009.10.021

Barber, L., Maltby, J., \& Macaskill, A. (2005). Angry memories and thoughts of revenge: The relationship between forgiveness and anger rumination. Personality and 
Individual Differences, 39(2), 253-262.

http://dx.doi.org/10.1016/j.paid.2005.01.006

Barlett, C. P., \& Anderson, C. A. (2011). Reappraising the Situation and Its Impact on Aggressive Behavior. Personality and Social Psychology Bulletin, 146167211423671. https://doi.org/10.1177/0146167211423671

Brown, R. P. (2004). Vengeance is mine: Narcissism, vengeance, and the tendency to forgive. Journal of Research in Personality, 38(6), 576-584. http://dx.doi.org/10.1016/j.jrp.2003.10.003

Byrne, B. M., Shavelson, R. J., \& Muthén, B. (1989). Testing for the equivalence of factor covariance and mean structures: the issue of partial measurement invariance. Psychological Bulletin, 105(3), 456-466. http://dx.doi.org/10.1037/0033-2909.105.3.456

Castro, S. M. D. J., Trentini, C. M., \& Riboldi, J. (2010). Teoria da resposta ao item aplicada ao Inventário de Depressão Beck. Revista brasileira de epidemiologia. Porto Alegre, 13(3), 487-501.

Cavalcanti, J. G., \& Pimentel, C. E. (2016). Personality and aggression: A contribution of the General Aggression Model. Estudos de Psicologia (Campinas), 33(3), 443451. http://dx.doi.org/10.1590/1982-02752016000300008

Chalmers, R. P. (2012). mirt: A Multidimensional Item Response Theory Package for the R Environment. Journal of Statistical Software, 48(6), 1-29.

Chen, F. F. (2007). Sensitivity of Goodness of Fit Indexes to Lack of Measurement Invariance. Structural Equation Modeling: A Multidisciplinary Journal, 14(3), 464-504. https://doi.org/10.1080/10705510701301834

Chen, F. F. (2008). What happens if we compare chopsticks with forks? The impact of making inappropriate comparisons in cross-cultural research. Journal of 
Personality and Social Psychology, 95(5), 1005-1018.

https://doi.org/10.1037/a0013193

Cota-McKinley, A. L., Woody, W. D., \& Bell, P. A. (2001). Vengeance: Effects of gender, age, and religious background. Aggressive Behavior, 27(5), 343-350. https://doi.org/10.1002/ab.1019

Credé, M., Harms, P., Niehorster, S., \& Gaye-Valentine, A. (2012). An evaluation of the consequences of using short measures of the Big Five personality traits. Journal of Personality and Social Psychology, 102(4), 874-888. https://doi.org/10.1037/a0027403

Damásio, B. F. (2013). Contribuições da Análise Fatorial Confirmatória Multigrupo (AFCMG) na avaliação de invariância de instrumentos psicométricos. Psico-USF, 18(2), 211-220. https://doi.org/10.1590/S1413-82712013000200005

Davidov, E., Meuleman, B., Cieciuch, J., Schmidt, P., \& Billiet, J. (2014). Measurement equivalence in cross-national research. Annual Review of Sociology, 40(1), 55-75. https://doi.org/10.1146/annurev-soc-071913-043137

Donnellan, M. B., Oswald, F. L., Baird, B. M., \& Lucas, R. E. (2006). The Mini-IPIP Scales: Tiny-yet-effective measures of the Big Five Factors of Personality. Psychological Assessment, 18(2), 192-203. https://doi.org/10.1037/10403590.18.2.192

Field, A. (2013). Discovering Statistics Using IBM SPSS Statistics. SAGE.

Forbes, G. B., Jobe, R. L., White, K. B., Bloesch, E., \& Adams-Curtis, L. E. (2005). Perceptions of Dating Violence Following a Sexualor Nonsexual Betrayal of Trust: Effects of Gender, Sexism, Acceptance of Rape Myths, and Vengeance Motivation. Sex Roles, 52(3), 165-173. https://doi.org/10.1007/s11199-005-12926 
Giammarco, E. A., \& Vernon, P. A. (2014). Vengeance and the Dark Triad: The role of empathy and perspective taking in trait forgivingness. Personality and Individual Differences, 67, 23-29. http://dx.doi.org/10.1016/j.paid.2014.02.010

Gollwitzer, M., \& Denzler, M. (2009). What makes revenge sweet: seeing the offender suffer or delivering a message? Journal of Experimental Social Psychology, 45(4), 840-844. https://doi.org/10.1016/j.jesp.2009.03.001

Gollwitzer, M., Meder, M., \& Schmitt, M. (2011). What gives victims satisfaction when they seek revenge? European Journal of Social Psychology, 41(3), 364-374. https://doi.org/10.1002/ejsp.782

Gosling, S. D., Rentfrow, P. J., \& Swann, W. B. (2003). A very brief measure of the BigFive personality domains. Journal of Research in Personality, 37, 504-528.

Greer, T., Berman, M., Varan, V., Bobrycki, L., \& Watson, S. (2005). We Are a Religious People; We Are a Vengeful People. Journal for the Scientific Study of Religion, 44(1), 45-57. https://doi.org/10.1111/j.1468-5906.2005.00264.x

Grobbink, L. H., Derksen, J. J. L., \& Marle, H. J. C. van. (2014). Revenge: An Analysis of Its Psychological Underpinnings. International Journal of Offender Therapy and Comparative Criminology, $0306624 X 13519963$. https://doi.org/10.1177/0306624X13519963

Hair, J. F. J., Black, W. C., Babin, B. J., \& Anderson, R. E. (2015). Multivariate Data Analysis (7 edition). Upper Saddle River, NJ: Prentice Hall.

Hooper, D., Coughlan, J., \& Mullen, M. (2008). Structural Equation Modeling: Guidelines for Determining Model Fit. Electronic Journal on Business Research Methods, 6(1), 53-60. 
Jonason, P. K., \& Webster, G. D. (2010). The dirty dozen: a concise measure of the dark triad. Psychological Assessment, 22(2), 420-432. https://doi.org/10.1037/a0019265

Jones, D. N., \& Paulhus, D. L. (2010). Different provocations trigger aggression in narcissists and psychopaths. Social Psychological and Personality Science, 1(1), 12-18. https://doi.org/10.1177/1948550609347591

Kline, P. (2013). Handbook of Psychological Testing. Routledge.

Lee, K., \& Ashton, M. C. (2005). Psychopathy, Machiavellianism, and narcissism in the Five-Factor Model and the HEXACO model of personality structure. Personality and Individual Differences, 38(7), 1571-1582. http://dx.doi.org/10.1016/j.paid.2004.09.016

Lee, K., \& Ashton, M. C. (2012). Getting mad and getting even: Agreeableness and Honesty-Humility as predictors of revenge intentions. Personality and Individual Differences, 52(5), 596-600. http://dx.doi.org/10.1016/j.paid.2011.12.004

Lorenzo-Seva, U., \& Ferrando, P. J. (2013). FACTOR 9.2 A Comprehensive Program for Fitting Exploratory and Semiconfirmatory Factor Analysis and IRT Models. Applied Psychological Measurement, 37(6), 497-498. https://doi.org/10.1177/0146621613487794

Lorenzo-Seva, U., Timmerman, M. E., \& Kiers, H. A. L. (2011). The Hull Method for Selecting the Number of Common Factors. Multivariate Behavioral Research, 46(2), 340-364. https://doi.org/10.1080/00273171.2011.564527

McCrae, R. R., \& Terracciano, A. (2005). Personality profiles of cultures: Aggregate personality traits. Journal of Personality and Social Psychology, 89(3), 407-425. https://doi.org/10.1037/0022-3514.89.3.407 
McCullough, M. (2008). Beyond Revenge: The Evolution of the Forgiveness Instinct. San Francisco: Jossey-Bass.

McCullough, M. E., \& Hoyt, W. T. (2002). Transgression-related motivational dispositions: Personality substrates of forgiveness and their links to the Big Five. Personality and Social Psychology Bulletin, 28(11), 1556-1573. https://doi.org/10.1177/014616702237583

McCullough, M. E., Bellah, C. G., Kilpatrick, S. D., \& Johnson, J. L. (2001). Vengefulness: relationships with forgiveness, rumination, well-being, and the big five. Personality and Social Psychology Bulletin, 27(5), 601-610. https://doi.org/10.1177/0146167201275008

McKee, I. R., \& Feather, N. T. (2008). Revenge, Retribution, and Values: Social Attitudes and Punitive Sentencing. Social Justice Research, 21(2), 138. https://doi.org/10.1007/s11211-008-0066-z

Milfont, T. L., \& Fischer, R. (2010). Testing measurement invariance across groups: Applications in cross-cultural research. International Journal of Psychological Research, 3(1), 111-130. https://doi.org/10.21500/20112084.857

Pailing, A., Boon, J., \& Egan, V. (2014). Personality, the Dark Triad and violence. Personality and Individual Differences, 67, 81-86. http://dx.doi.org/10.1016/j.paid.2013.11.018

R Development Core Team. (2015). R: A language and environment for statistical computing. Retrieved from https://cran.r-project.org/doc/manuals/fullrefman.pdf

Rammstedt, B., \& Beierlein, C. (2014). Can't We Make It Any Shorter? Journal of Individual Differences, 35(4), 212-220. https://doi.org/10.1027/16140001/a000141 
Rammstedt, B., \& John, O. P. (2007). Measuring personality in one minute or less: A 10item short version of the Big Five Inventory in English and German. Journal of Research in Personality, 41(1), 203-212. https://doi.org/10.1016/j.jrp.2006.02.001

Rasmussen, K. (2015). Entitled vengeance: A meta-analysis relating narcissism to provoked aggression. Aggressive Behavior, 42(4), 362-379. https://doi.org/10.1002/ab.21632

Rhemtulla, M, Brosseau-Liard, P. É., \& Savalei, V. (2012). When Can Categorical Variables Be Treated as Continuous? A Comparison of Robust Continuous and Categorical SEM Estimation Methods Under Suboptimal Conditions. Psychological Methods, 17, 354-373.

Rosseel, Y. (2012). lavaan: An R Package for Structural Equation Modeling. Journal of Statistical Software, 48(2), 1-36.

Ruggi, S., Gilli, G., Stuckless, N., \& Oasi, O. (2012). Assessing Vindictiveness: Psychological Aspects by a Reliability and Validity Study of the Vengeance Scale in the Italian Context. Current Psychology, 31(4), 365-380. https://doi.org/10.1007/s12144-012-9153-2

Samejima, F. (1968). Estimation of Latent Ability Using a Response Pattern of Graded Scores1. ETS Research Bulletin Series, 1968(1), i-169. https://doi.org/10.1002/j.2333-8504.1968.tb00153.x

Satici, S., Can, G., \& Akin, A. (2015). The Vengeance Scale: Turkish adaptation study. Anatolian Journal of Psychiatry, 1. https://doi.org/10.5455/apd.170563

Sawada, M., \& Hayama, D. (2012). Dispositional Vengeance and Anger on Schadenfreude. Psychological Reports, 111(1), 322-334. https://doi.org/10.2466/16.07.21.PR0.111.4.322-33 
Schmitt, D. P., \& Allik, J. (2005). Simultaneous administration of the Rosenberg SelfEsteem Scale in 53 nations: exploring the universal and culture-specific features of global self-esteem. Journal of Personality and Social Psychology, 89(4), 623642.

Schumann, K., \& Ross, M. (2010). The Benefits, Costs, and Paradox of Revenge. Social and Personality Psychology Compass, 4(12), 1193-1205.

https://doi.org/10.1111/j.1751-9004.2010.00322.x

Sibley, C. G., Nils Luyten, Missy Purnomo, Annelise Mobberley, Liz W. Wootton, Matthew D. Hammond, ... Andrew Robertson. (2011). The Mini-IPIP6: Validation and extension of a short measure of the Big-Six factors of personality in New Zealand. New Zealand Journal of Psychology, 40(3).

Sjöström, A., \& Gollwitzer, M. (2015). Displaced revenge: Can revenge taste "sweet" if it aims at a different target? Journal of Experimental Social Psychology, 56, 191202. https://doi.org/10.1016/j.jesp.2014.09.016

Stuckless, N., \& Goranson, R. (1992). The Vengeance Scale: Development of a measure of attitudes toward revenge. Journal of Social Behavior and Personality, 7(1), 2542.

Tabachnick, B. G., \& Fidell, L. S. (2013). Using Multivariate Statistics (6 edition). Pearson.

United Nations Office on Drugs and Crime. (2014). Global study on homicide. Vienna: (United Nations publication, Sales No. 14.IV.1. Retrieved from http://www.unodc.org/documents/gsh/pdfs/2014_GLOBAL_HOMICIDE_BOOK _web.pdf 
Uysal, R., \& Satici, S. A. (2014). The Mediating and Moderating Role of Subjective Happiness in the Relationship between Vengeance and Forgiveness. Educational Sciences: Theory and Practice, 14(6), 2097-2105.

Widaman, K. F., Little, T. D., Preacher, K. J., \& Sawalani, G. M. (2011). On creating and using short forms of scales in secondary research. In K. H. Trzesniewski, M. B. Donnellan, \& R. E. Lucas (Eds.), Secondary data analysis: An introduction for psychologists (pp. 39-61). Washington, DC, US: American Psychological Association.

Yarkoni, T. (2010). The Abbreviation of Personality, or how to Measure 200 Personality Scales with 200 Items. Journal of Research in Personality, 44(2), 180-198. https://doi.org/10.1016/j.jrp.2010.01.002 


\section{APPENDIX - ITEMS OF THE VENGEANCE SCALE SHORT VERSION (ENGLISH AND PORTUGUESE VERSIONS) **}

Item 01. It's not worth my time or effort to pay back someone who has wronged me. (R)* Item 02. It is important for me to get back at people who have hurt me. * Item 03 . I try to even the score with anyone who hurts me.

Item 04 . It is always better not to seek vengeance. $(\mathrm{R})$

Item 05 . There is nothing wrong in getting back at someone who has hurt you.*

Item 06. I don't just get mad, I get even. *

Item 07 . I am not a vengeful person. $(\mathrm{R})^{*}$

Item 08. I believe in the motto "An eye for an eye, a tooth for a tooth."

Item 09. If I am wronged, I can't live with myself unless I get revenge.

Item 10. Honor requires that you get back at someone who has hurt you.

Item 01. Não vale meu tempo ou esforço me vingar de alguém que é injusto comigo. (R)* Item 02. Para mim, é importante me vingar de pessoas que me machucaram. *

Item 03. Tento igualar a situação com qualquer um que me machuca.

Item 04. É sempre melhor não buscar vingança. (R)

Item 05. Não há nada errado em se vingar de alguém que te machucou.*

Item 06. Não fico apenas com raiva, eu dou o troco. *

Item 07. Não sou uma pessoa vingativa. (R)*

Item 08. Acredito no pensamento: "Olho por olho, dente por dente".

Item 09. Se eu for injustiçado(a), não consigo me acalmar até me vingar.

Item 10. Honra requer que você se vingue daqueles que lhe machucaram.

Note: * Ultra-short items; ** In the full scale, these items are, respectively, 01, 02, 03, 04, 06, 07, 09, 10, 14, and 15. 


\section{Item Information Curves}

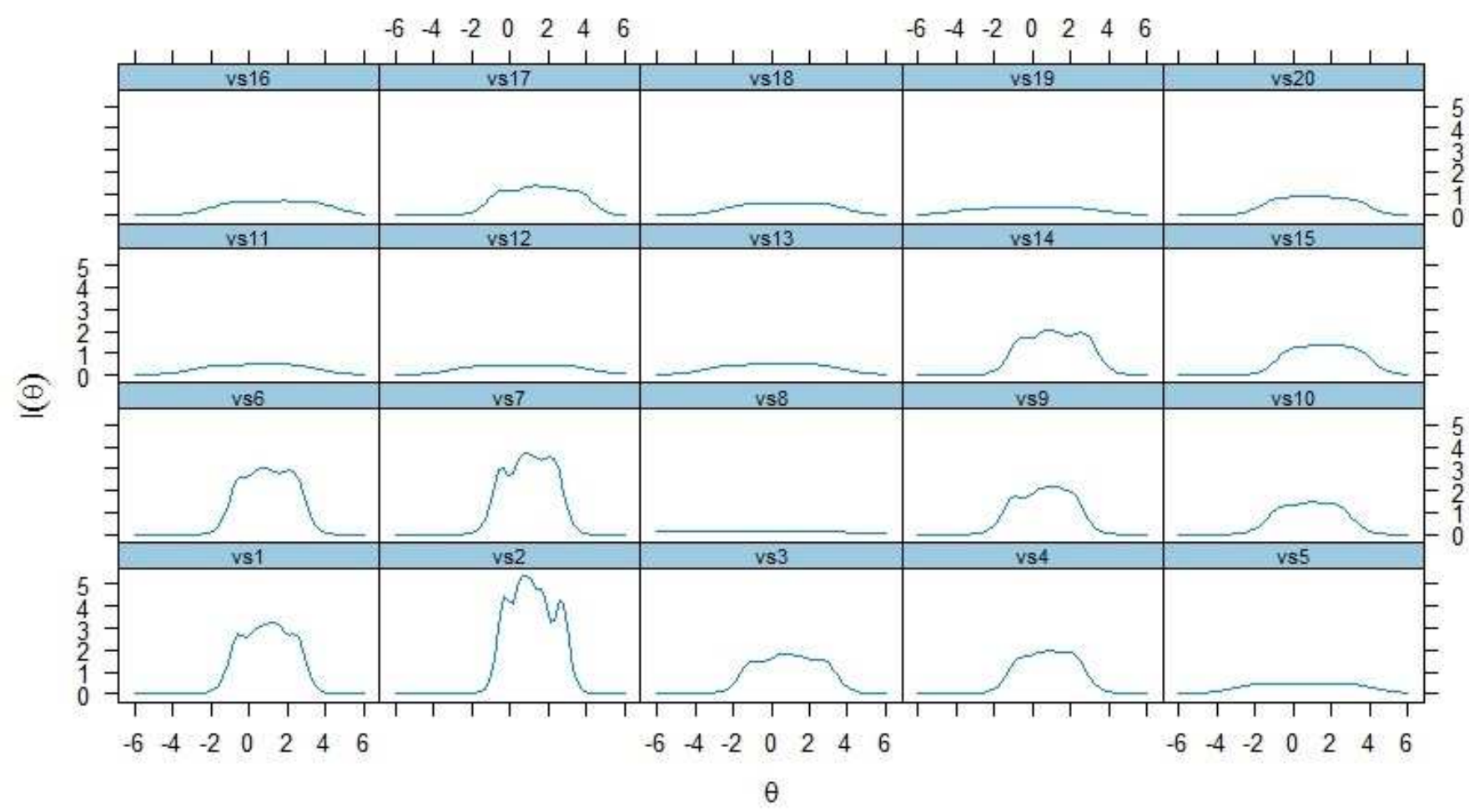

Figure 1. Item Information Curves 


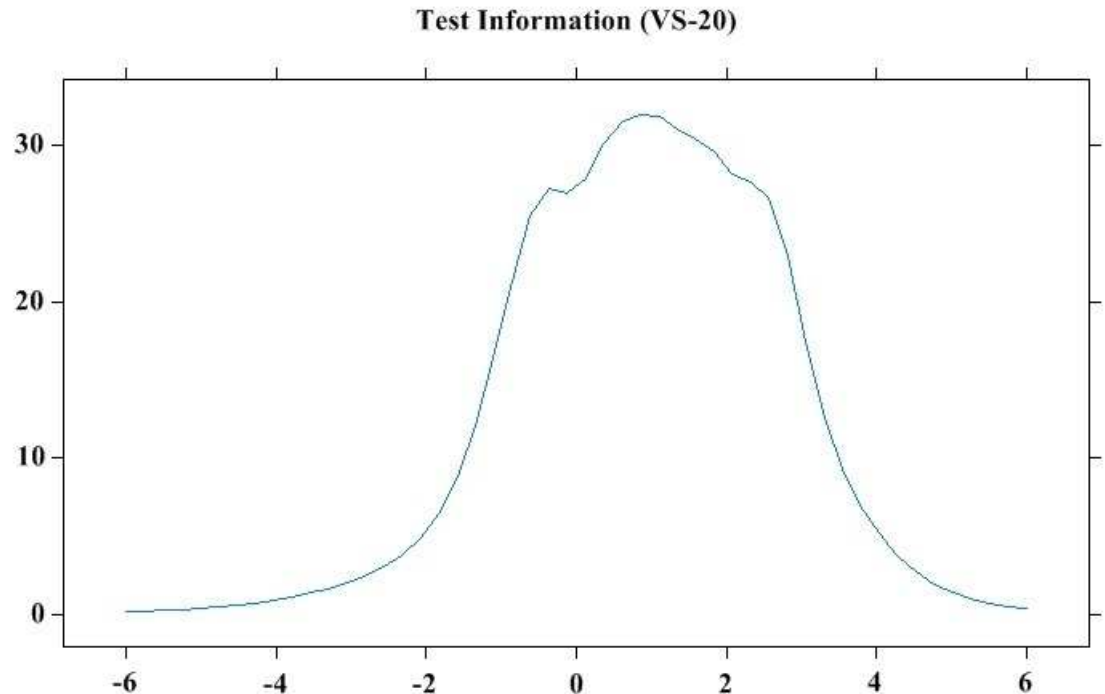

Test Information (VS-10)

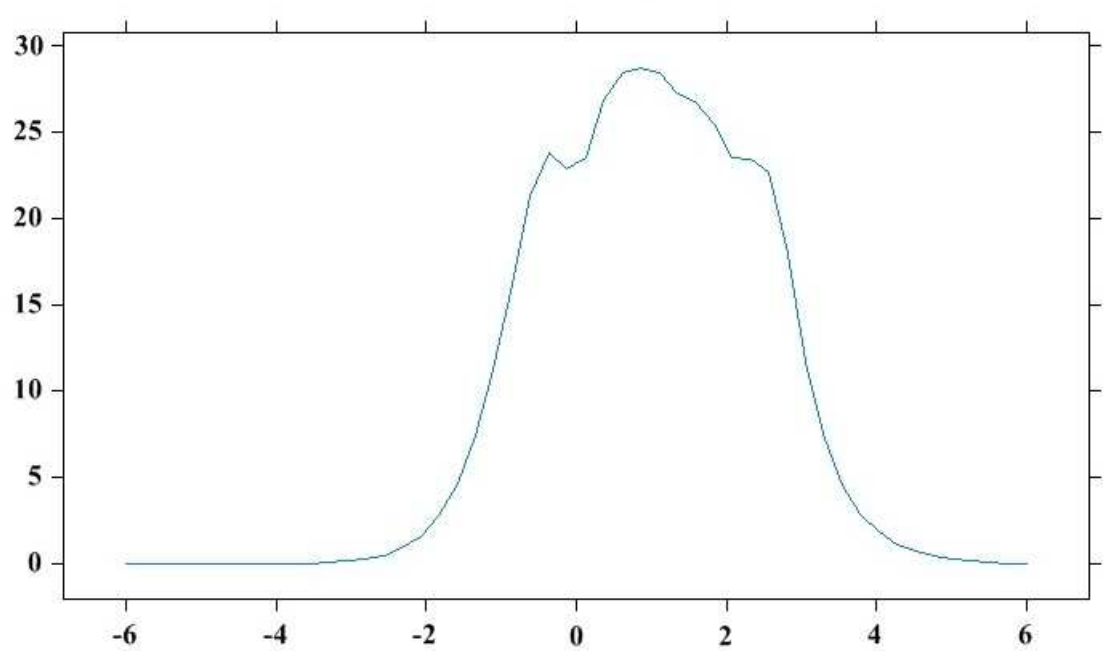

Test Information (VS-5)

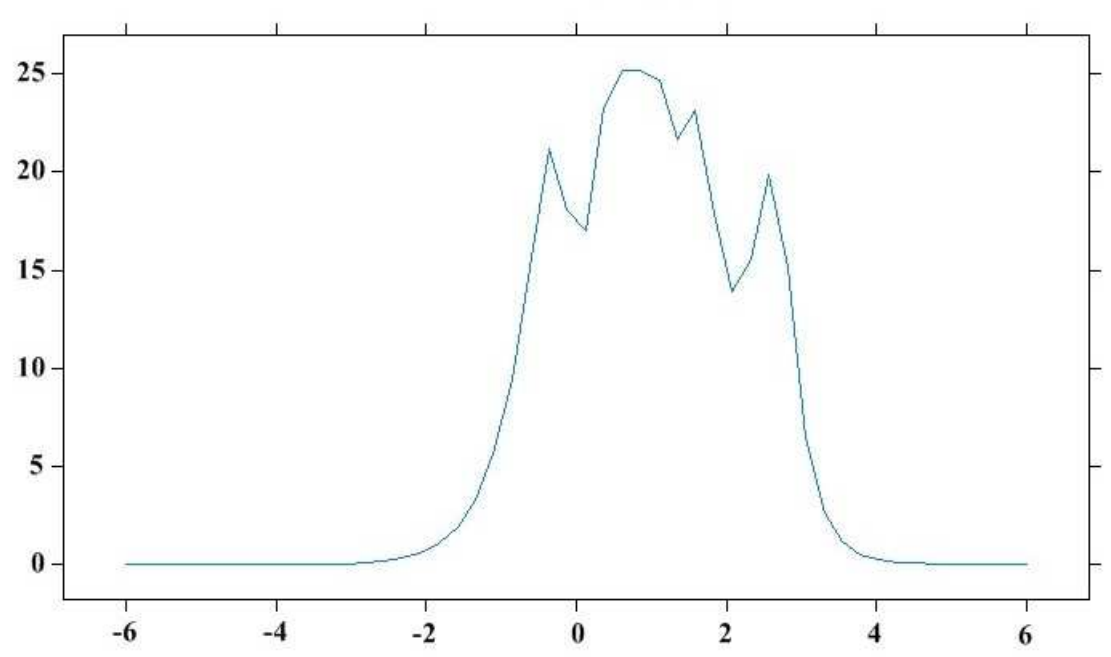

Figure 2. Test Information Curves of the Vengeance Scale with 20, 10, and 5 items. 
Table 1. Factorial structure, discrimination, and threshold parameters of the VS

\begin{tabular}{|c|c|c|c|c|c|c|c|c|c|}
\hline Item & Factor & $h^{2}$ & $a$ & $b_{1}$ & $b_{2}$ & $b_{3}$ & $b_{4}$ & $b_{5}$ & $b_{6}$ \\
\hline Item 2 & 0.88 & 0.77 & 4.17 & -0.32 & 0.44 & 0.76 & 1.12 & 1.70 & 2.69 \\
\hline Item 7 & 0.84 & 0.71 & 3.45 & -0.53 & 0.45 & 0.84 & 1.26 & 1.94 & 2.40 \\
\hline Item 1 & 0.83 & 0.69 & 3.23 & -0.58 & 0.34 & 0.92 & 1.29 & 1.59 & 2.47 \\
\hline Item 6 & 0.81 & 0.66 & 3.12 & -0.56 & 0.29 & 0.73 & 1.21 & 1.93 & 2.48 \\
\hline Item 9 & 0.80 & 0.64 & 2.61 & -0.97 & 0.17 & 0.70 & 1.08 & 1.51 & 2.17 \\
\hline Item 14 & 0.77 & 0.59 & 2.56 & -0.62 & 0.48 & 0.89 & 1.51 & 2.54 & 2.89 \\
\hline Item 3 & 0.75 & 0.57 & 2.39 & -1.03 & 0.17 & 0.56 & 1.11 & 1.76 & 2.84 \\
\hline Item 4 & 0.73 & 0.53 & 2.48 & -0.69 & 0.25 & 0.81 & 1.26 & 1.85 & 2.30 \\
\hline Item 10 & 0.73 & 0.53 & 2.14 & -0.69 & 0.29 & 0.77 & 1.22 & 1.86 & 2.44 \\
\hline Item 15 & 0.69 & 0.48 & 2.09 & -0.17 & 0.85 & 1.42 & 2.05 & 2.45 & 3.42 \\
\hline Item 17 & 0.69 & 0.47 & 2.07 & -0.51 & 0.76 & 1.10 & 1.71 & 2.38 & 3.55 \\
\hline Item 20 & 0.61 & 0.37 & 1.65 & -0.85 & 0.13 & 0.46 & 1.16 & 1.88 & 3.10 \\
\hline Item 16 & 0.57 & 0.33 & 1.45 & -1.10 & 0.31 & 1.16 & 1.92 & 2.51 & 3.62 \\
\hline Item 5 & 0.57 & 0.32 & 1.23 & -2.06 & -0.69 & 0.55 & 1.34 & 2.18 & 3.31 \\
\hline Item 13 & 0.54 & 0.29 & 1.24 & -2.41 & -0.90 & -0.03 & 1.07 & 1.87 & 2.79 \\
\hline Item 18 & 0.51 & 0.26 & 1.34 & -1.53 & -0.28 & 0.67 & 1.38 & 2.32 & 2.98 \\
\hline Item 12 & 0.51 & 0.26 & 1.18 & -1.94 & -0.16 & 0.35 & 1.11 & 1.99 & 3.23 \\
\hline Item 11 & 0.50 & 0.25 & 1.24 & -1.82 & -0.13 & 0.42 & 1.54 & 2.18 & 2.58 \\
\hline Item 19 & 0.47 & 0.22 & 1.07 & -2.97 & -1.05 & -0.05 & 0.65 & 1.44 & 2.71 \\
\hline Item 8 & 0.37 & 0.14 & 0.71 & -4.97 & -3.18 & -0.83 & -0.03 & 1.09 & 2.46 \\
\hline
\end{tabular}

Note: Hull extraction method; $\mathrm{h}^{2}=$ communalities; $\mathrm{a}=$ discrimination parameter; $\mathrm{b}_{1}-$ $\mathrm{b}_{6}=$ threshold. 
Table 2. Item parameters of the VS short version, VS-10.

\begin{tabular}{llllllll}
\hline Item & $a$ & $b_{1}$ & $b_{2}$ & $b_{3}$ & $b_{4}$ & $b_{5}$ & $b_{6}$ \\
\hline Item 2 & 4.83 & -0.31 & 0.42 & 0.75 & 1.11 & 1.67 & 2.64 \\
Item 7 & 4.07 & -0.51 & 0.43 & 0.82 & 1.23 & 1.88 & 2.32 \\
Item 6 & 3.03 & -0.56 & 0.28 & 0.73 & 1.22 & 1.94 & 2.48 \\
Item 1 & 3.36 & -0.58 & 0.33 & 0.92 & 1.28 & 1.56 & 2.42 \\
Item 9 & 2.54 & -0.98 & 0.17 & 0.71 & 1.10 & 1.52 & 2.17 \\
Item 14 & 2.45 & -0.63 & 0.50 & 0.91 & 1.54 & 2.59 & 2.95 \\
Item 4 & 2.23 & -0.71 & 0.28 & 0.85 & 1.30 & 1.90 & 2.36 \\
Item 3 & 2.47 & -1.03 & 0.17 & 0.56 & 1.10 & 1.73 & 2.80 \\
Item 10 & 2.23 & -0.68 & 0.29 & 0.76 & 1.22 & 1.84 & 2.40 \\
Item 15 & 2.05 & -0.16 & 0.86 & 1.44 & 2.08 & 2.47 & 3.46 \\
\hline
\end{tabular}

Note $\mathrm{a}=$ discrimination; $\mathrm{b}_{1}-\mathrm{b}_{6}=$ threshold 
Table 3. Item parameters of the VS ultrashort version - VS-5.

\begin{tabular}{cccccccc}
\hline Item & $a$ & $b_{1}$ & $b_{2}$ & $b_{3}$ & $b_{4}$ & $b_{5}$ & $b_{6}$ \\
\hline Item 1 & 3.81 & -0.57 & 0.33 & 0.90 & 1.24 & 1.51 & 2.36 \\
Item 2 & 6.68 & -0.31 & 0.41 & 0.73 & 1.07 & 1.61 & 2.66 \\
Item 6 & 2.79 & -0.58 & 0.27 & 0.73 & 1.25 & 2.00 & 2.58 \\
Item 7 & 3.62 & -0.53 & 0.43 & 0.82 & 1.25 & 1.93 & 2.39 \\
Item 9 & 2.33 & -1.02 & 0.16 & 0.72 & 1.12 & 1.56 & 2.24 \\
\hline Note: $:$ a discrimination; $\mathrm{b}_{1}-\mathrm{b}_{6}=$ threshold & & &
\end{tabular}


Table 4. Measurement invariance and partial invariance of the VS-10 and VS-10 across countries and gender.

\begin{tabular}{cccccc}
\hline & $\begin{array}{c}\text { Models of } \\
\text { Invariance }\end{array}$ & CFI & RMSEA & $\Delta$ CFI & $\Delta$ RMSEA \\
\hline Country - VS-10 & Configural & .947 & .073 & - & - \\
BR $(n=220)$ & Metric & $.924(.946)$ & $.082(.085)$ & $.023(.001)$ & $.009(.012)$ \\
UK $(n=205)$ & Scalar & $.843(.925)$ & $.112(.095)$ & $.081(.021)$ & $.030(.010)$ \\
\hline Country - VS-5 & Configural & .993 & .040 & - & - \\
& Metric & $.953(.994)$ & $.090(.046)$ & $.040(-.001)$ & $.050(.006)$ \\
& Scalar & $.852(.969)$ & $.141(.086)$ & $.101(.025)$ & $.051(.040)$ \\
\hline Gender - VS-10 & Configural & .930 & .083 & - & - \\
Female $(n=324)$ & Metric & .930 & .078 & .000 & .005 \\
Male $(n=99)$ & Scalar & .927 & .075 & .003 & .002 \\
\hline Gender - VS-5 & Configural & .992 & .045 & - & - \\
& Metric & .992 & .039 & .000 & .006 \\
& Scalar & .984 & .047 & .008 & .009 \\
\hline
\end{tabular}

Note. $\Delta=$ differences between the current and the previous model. Results of partial invariance are in brackets. See text for explanation. 